\title{
Impaired Activity-Dependent Plasticity of Quantal Amplitude at the Neuromuscular Junction of Rab3A Deletion and Rab3A Earlybird Mutant Mice
}

\author{
Xueyong Wang, ${ }^{1}$ Qingbo Wang, ${ }^{1}$ Shuzhang Yang, ${ }^{2}$ Maja Bucan, ${ }^{3}$ Mark M. Rich, ${ }^{1}$ and Kathrin L. Engisch ${ }^{1}$ \\ ${ }^{1}$ Department of Neuroscience, Cell Biology and Physiology, Boonshoft School of Medicine, Wright State University, Dayton, Ohio 45435, ${ }^{2}$ Department of \\ Neuroscience, University of Texas Southwestern Medical Center, Dallas, Texas 75390, and ${ }^{3}$ Department of Genetics, University of Pennsylvania, \\ Philadelphia, Pennsylvania 19104
}

Rab3A is a small GTPase associated with synaptic vesicles that is required for some forms of activity-dependent plasticity. It is thought to regulate the number of vesicles that fuse through an effect on docking, vesicle maturation, or mobilization. We recently showed that at the neuromuscular junction, loss of Rab3A led to an increase in the occurrence of miniature endplate currents (mepcs) with abnormally long half-widths (Wang et al., 2008). Here we show that such events are also increased after short-term activity blockade, and this process is not Rab3A-dependent. However, in the course of these experiments we discovered that the homeostatic increase in mepc amplitude after activity blockade is diminished in the Rab3A deletion mouse and abolished in the Rab3A Earlybird mouse which expresses a point mutant of Rab3A. We show that homeostatic plasticity at the neuromuscular junction does not depend on tumor necrosis factor $\alpha$, is not accompanied by an increase in the levels of VAChT, the vesicular transporter for ACh, and confirm that there is no increase in ACh receptors at the junction, three characteristics distinct from that of CNS homeostatic plasticity. Activity blockade does not produce time course changes in mepcs that would be consistent with a fusion pore mechanism. We conclude that Rab3A is involved in a novel presynaptic mechanism to homeostatically regulate the amount of transmitter in a quantum.

\section{Introduction}

Neural networks respond to changes in activity levels with physiological alterations that bring network activity back to its normal level. This homeostatic plasticity involves changes in transmitter release probability, intrinsic excitability, and quantal amplitude - the postsynaptic response to a single vesicle of transmitter (Marder and Goaillard, 2006; Rich and Wenner, 2007; Turrigiano, 2008; Pozo and Goda, 2010). Similar to two other forms of activity-dependent plasticity, long-term potentiation and longterm depression, homeostatic plasticity of quantal amplitude occurs mainly through the up- and downregulation of glutamate receptors in the surface membrane (Lissin et al., 1998; O'Brien et al., 1998; Turrigiano et al., 1998; Wierenga et al., 2005; Shepherd et al., 2006). However, homeostatic changes in amount of vesicular transporters for excitatory and inhibitory transmitters have also been observed (De Gois et al., 2005; Wilson et al., 2005; Hartman et al., 2006), which suggests that quantal amplitude might be regulated by pre- and postsynaptic mechanisms in tandem.

\section{Received Oct. 7, 2010; revised Nov. 28, 2010; accepted Jan. 12, 2011}

This work was supported by a grant from the National Institutes of Health (P01 NS057228). We thank Dr. Martin Pinter (Emory University, Atlanta, GA) for supplying mepc acquisition and analysis software. We thank A. Koesters for genotyping animals, K. Kapolka and L. Rich for image analysis, and B. Vijayakumar and L. Wang for data analysis.

Correspondence should be addressed to Dr. Kathrin L. Engisch, Department of Neuroscience, Cell Biology and Physiology, 143 Biological Sciences II, Wright State University, 3640 Colonel Glenn Highway, Dayton, OH 45435. E-mail: Kathrin.engisch@wright.edu.

DOI:10.1523/JNEUROSCI.5278-10.2011

Copyright $\odot 2011$ the authors $\quad 0270-6474 / 11 / 313580-09 \$ 15.00 / 0$
We have established that activity blockade at the mouse neuromuscular junction in vivo induces an increase in miniature endplate current (mepc) amplitude (Wang et al., 2005). In contrast to the studies in hippocampal and cortical dissociated and slice cultures, there is no activity-dependent change in postsynaptic receptor levels, based on quantification of fluorescent $\alpha$-bungarotoxin ( $\alpha$-Bgtx) intensity in confocal images. Therefore it appears likely that homeostatic regulation of quantal amplitude at this synapse relies on a presynaptic mechanism.

Rab3A is a synaptic vesicle protein that is not essential for synaptic transmission but is required for several forms of synaptic plasticity. Long-term potentiation at mossy fiber-CA3 synapses and cortical-amygdala synapses, and BDNF-induced potentiation of spontaneous synaptic currents in hippocampal cultures, are abolished in Rab3 $A^{-l-}$ mice (Castillo et al., 1997; ThakkerVaria et al., 2001; Huang et al., 2005). In each of these cases, modulation of classic presynaptic functions such as probability of release and frequency of miniature synaptic currents are involved. Rab3A has not previously been thought to regulate quantal characteristics, but we recently found that loss of Rab3A led to an increase in occurrence of abnormally shaped mepcs at the neuromuscular junction (Wang et al., 2008). The abnormal mepcs we identified in that study are similar to events that have been referred to in the literature as giant miniature endplate potentials, or Gmepps (Alkadhi, 1989). Gundersen (1990) used a tetrodotoxin cuff to block impulse activity at the sciatic nerve of rat for 30-59 d, and reported that in addition to an increase in quantal content (evoked release), there was a $\sim 10$-fold increase 
in the occurrence of Gmepps. In our previous study of short-term blockade, we did not analyze the relative occurrence of abnormal mepcs. Another study of short-term activity blockade also did not report whether Gmepps were increased (Snider and Harris, 1979). Here we show that abnormal mepcs are increased following short-term activity blockade. Although Rab3A function is not required for this modulation of abnormal mepcs, surprisingly, we found that it is required for the homeostatic increase in quantal amplitude.

\section{Materials and Methods}

Animals. Rab3a $a^{+/-}$heterozygous mice were bred and genotyped as previously described (Kapfhamer et al., 2002; Wang et al., 2008). Rab3A ${ }^{E b d / E b d}$ mice were identified in an ENU ( $N$-ethyl- $N$-nitrosourea)-mutagenesis screen of $\mathrm{C} 57 \mathrm{BL} / 6 \mathrm{~J}$ mice, and after a cross to $\mathrm{C} 3 \mathrm{H} / \mathrm{HeJ}$, were backcrossed for 3 generations to C57BL/6J (Kapfhamer et al., 2002). Rab3A ${ }^{+/ E b d}$ heterozygous mice were bred at Wright State University and genotyped in a two-step procedure: step 1, a PCR with RabF1 and Dcaps3R as primers; and step 2, a digestion with enzyme Bsp1286I (New England Biolabs) that distinguishes the Earlybird mutant by its different base pair products. TNF $\alpha^{-1-}$ mice (B6.129S6-Tnf $\left.{ }^{\mathrm{tm} 1 \mathrm{GK1}} / \mathrm{J}\right)$ and controls (C57BL/ 6J) were purchased from Jackson Laboratory and housed briefly at Wright State University. All animal procedures were approved by the Laboratory Animal Care and Use Committee of Wright State University. Males and females were used between the ages of 2.5 and 3.5 months.

Surgery. Animals were anesthetized with $4 \%$ chloral hydrate and a SILASTIC cuff placed around the sciatic nerve of one leg. The cuff was attached to an Alzet osmotic minipump (Durect) containing $850 \mu \mathrm{m}$ tetrodotoxin (TTX) (Alomone Labs). The pump was placed subcutaneously in the back. Additional details have been published previously (Wang et al., 2010). Experiments were performed on day 7 or day 8 after cuff placement.

Physiology. Two-electrode voltage-clamp recordings of mepcs were performed as previously described (Wang et al., 2005, 2008). Extracellular recording solution consisted of the following (in $\mathrm{mm}$ ): $118 \mathrm{NaCl}, 3.45$ $\mathrm{KCl}, 11$ dextrose, $26.2 \mathrm{NaHCO}_{3}, 1.7 \mathrm{NaH}_{2} \mathrm{PO}_{4}, 0.7 \mathrm{MgSO}_{4}, 2 \mathrm{CaCl}_{2}$, bubbled with $5 \% \mathrm{CO}_{2}-95 \% \mathrm{O}_{2}$. Before experiments, muscle fibers were crushed at a point far from the endplate band, to prevent contraction during stimulation (data not presented here). Fibers were voltageclamped to a holding potential of $-45 \mathrm{mV}$.

Analysis of mepcs. In each leg, 10-18 fibers were sampled. Recordings were typically $2 \mathrm{~min}$. Miniature endplate current traces were aligned using custom software and an average mepc trace was obtained for each fiber. The amplitude of this average mepc trace was taken as the amplitude for the fiber. The decay of an individual mepc was determined as the time required for the mepc amplitude to decline to $1 / 2.7$, or $37 \%$, and fiber means were the average of decays of all mepcs recorded in that fiber. Means were averaged across fibers for each leg, and data were compared between untreated and TTX-treated legs across animals with a paired $t$ test. Only fibers with $>40$ mepcs and animals with at least 6 acceptable fibers on each side were included in analyses. Unless noted otherwise, abnormal mepcs have been included in samples, but in a subset of data in which they were removed, results were not different. Abnormal mepcs were defined as mepcs with half-widths that fell outside of the $p=0.05$ value of a Gaussian fit to the frequency distribution. Fits were performed in OriginPro 8 (OriginLab) (see Wang et al., 2008 for additional details).

Immunohistochemistry. Animals were perfused with 4\% paraformaldehyde, and the tibialis anterior muscle was postfixed with $4 \%$ paraformaldehyde, cryoprotected in $15 \%$ sucrose solution overnight, and frozen in liquid nitrogen. Muscles were sectioned at $6 \mu \mathrm{m}$ thickness; thicker sections gave highly variable Rab3A immunolabeling. Antibodies used were anti-Rab3A (monoclonal clone 42.2, specific for Rab3A, Synaptic Systems), 1:800; anti-Rab3 (monoclonal clone 42.1, recognizes Rab3A, -B, -C, and -D, Synaptic Systems), 1:200, both detected with the mouseon-mouse (M.O.M.) procedure of Vector Laboratories, with biotinylated anti-mouse IgG, and FITC avidin; anti-vesicular acetylcholine transporter VAChT (polyclonal goat, BD Biosciences, no longer available), 1:4000, detected with FITC-anti-goat (Jackson ImmunoResearch);
anti-SV2B (polyclonal, Synaptic Systems), 1:200, detected with CY5donkey-anti-rabbit (Jackson ImmunoResearch). Rhodamine- $\alpha$-bungarotoxin, $2 \mu \mathrm{g} / \mathrm{ml}$ (Invitrogen) was added in the final rinse steps to label acetylcholine receptors.

Confocal microscopy. $z$-axis stacks of images at sequential focal planes (1.0 $\mu \mathrm{m}$ separation) of neuromuscular junctions were obtained using an Olympus Fluoview FV 1000 confocal microscope and a $60 \times$ oil, 1.35 numerical aperture objective. The illustrated images are flat-plane infocus projections obtained from $z$-series images using Fluoview software.

Image analysis. Images were analyzed using Image Pro Plus (Media Cybernetics). To determine intensity of labeling, extended depth-of-field flat-plane images of $\alpha$-bungarotoxin labeling were generated using the maximum intensity algorithm, and areas of interest (AOIs) were drawn by hand, using the inside edge of the bright rimming of $\alpha$-Bgtx labeling as a guide. Average pixel intensities for multiple areas of interest (10-30) were used to obtain overall means for each label at each neuromuscular junction. In addition, a ratio of VAChT/SV2B was calculated for each AOI, and averaged to obtain a single ratio per neuromuscular junction. Between 12 and 20 neuromuscular junctions were sampled for each leg; comparisons between the untreated and TTX-treated legs across animals were made using paired $t$ tests.

\section{Results}

Rab3A is a member of a gene subfamily with other members, Rab3B, $-\mathrm{C}$, and $-\mathrm{D}$, which share as much as $84 \%$ homology (Cheng et al., 2002). It is clear that Rab3 members can substitute for loss of Rab3A because the Rab3A deletion mouse is difficult to distinguish from wild-type animals, whereas combination of Rab3A deletion with that of any other Rab3 gene is associated with neonatal death (Schlüter et al., 2004). Furthermore, the most dramatic effects of Rab3A loss have been observed at synapses that express only Rab3A, like the mossy fiber-CA3 synapse, at which PKA-dependent long-term potentiation is completely abolished (Castillo et al., 1997). Rab3A expression has been demonstrated at the rodent neuromuscular junction (Matteoli et al., 1991; Mizoguchi et al., 1992), but it is not known whether other isoforms are present. To address this issue, we imaged neuromuscular junctions of Rab3A $A^{-/-}$mice using confocal microscopy after exposure to a pan-Rab3 antibody from Synaptic Systems that recognizes all Rab3 isoforms. We found in two experiments that a subset of Rab3A $A^{-1-}$ neuromuscular junctions had intensity values in the range of wild-type values (Fig. $1 A$, experiment 1 , 3 of 13; experiment 2, 5 of 16; see images $i$ and $i v$ ). Furthermore, except for 1 junction in experiment 1 , and 2 junctions in experiment 2, the shape of the neuromuscular junction was visible in the Rab3 channel (Fig. $1 A$, image ii). This result demonstrates that some neuromuscular junctions contain significant amounts, and almost all neuromuscular junctions contain at least a small amount, of a Rab3 protein that is not Rab3A. When an experiment was performed using the Rab3A-specific antibody from Synaptic Systems, all the values for the $R a b 3 A^{-1-}$ animal were below the lowest value in the wild-type animal, and neuromuscular junction shape was not visible in any image (Fig. $1 B$, images $i, i i)$.

We wanted to determine whether short-term activity blockade caused an increase in abnormal mepcs, and whether Rab3A played a role in this modulation, since we had previously found that loss of Rab3A alone caused an increase in abnormal mepcs (Wang et al., 2008). However, the presence of other Rab3 isoforms demonstrated in Figure $1 A$ confounds interpretation of results in the Rab3 $A^{-1-}$ mouse. Although the Rab3 quadruple deletion mouse, $R a b 3 A B C D^{-1-}$, has been created (Schlüter et al., 2004), it is not possible to perform the activity blockade experiment at the adult neuromuscular junction in vivo because the mouse dies soon after birth. Fortunately, the Rab3A Earlybird 


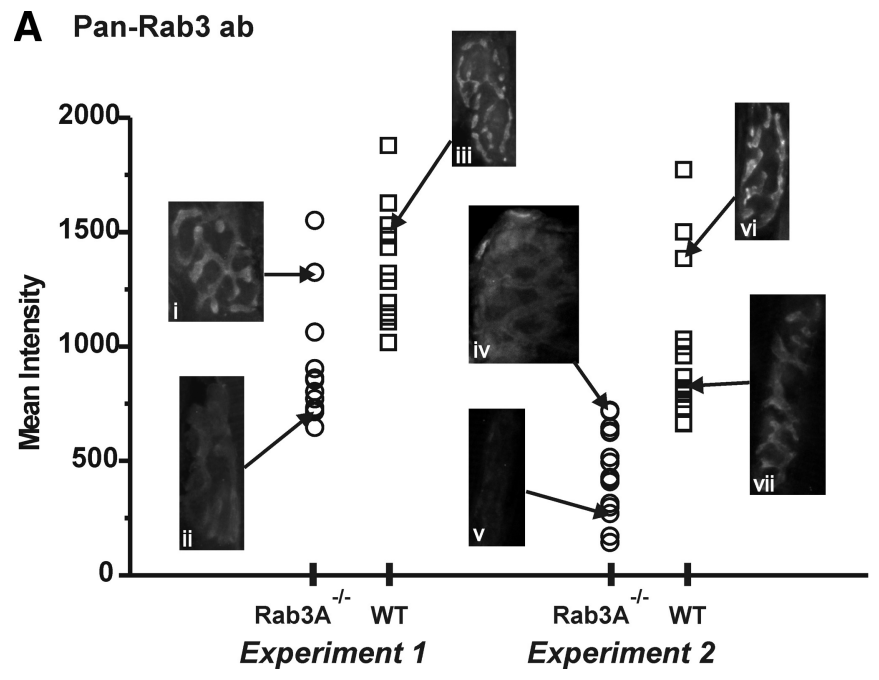

\section{B Rab3A-specific ab}

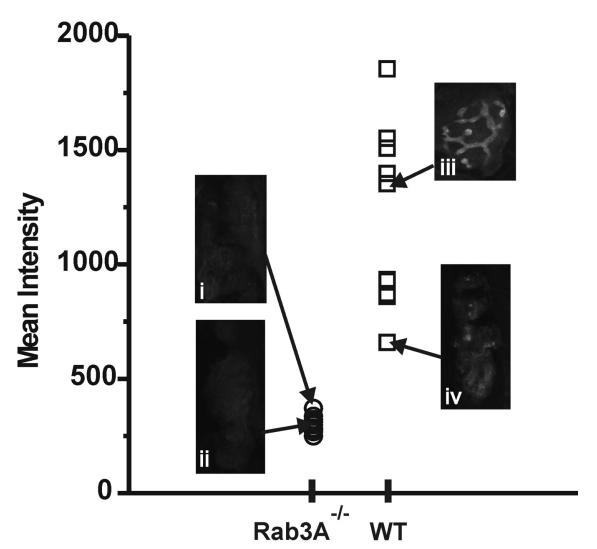

Figure 1. The mouse neuromuscular junction expresses at least one other Rab3 isoform in addition to Rab3A. $\boldsymbol{A}$, Scatter plot of mean intensity values in two experiments for individual neuromuscular junctions from Rab3A $A^{-1-}$ and wild-type sibling mice, labeled with a pan-Rab3 antibody (clone 42.1, Synaptic Systems). Flat-plane images of neuromuscular junctions with the indicated mean intensities were selected to show background levels ( $\boldsymbol{v})$, low levels of immunoreactivity (ii, iv, vii) and high levels of immunoreactivity (i, iii, vi). $\boldsymbol{B}$, Scatter plot of mean intensity values in one experiment for individual neuromuscular junctions from a Rab3A ${ }^{-1-}$ and wild-type sibling mouse, labeled with a Rab3A-specfic antibody that does not recognize Rab3B, $-C$, or -D (clone 42.2, Synaptic Systems). Intensity values for Rab3A-/- neuromuscular junctions were not above background (i, ii). The shape of the neuromuscular junction is visible in the Rab3A $+/+$ wild-type (WT) neuromuscular junction with the lowest intensity (iv). Mean intensity for a neuromuscular junction was obtained by circling areas of interest, obtaining the mean intensity for each AOI, and averaging across AOls for that junction. The images in $\boldsymbol{A}$ and $\boldsymbol{B}$ are not enhanced or modified; all are at the same magnification and zoom. Values are not background-subtracted.

mutant survives to adulthood (Kapfhamer et al., 2002). It has a single point mutation, D77G, in one of the guanine nucleotide-binding regions of Rab3A. The mouse was named for its shortened circadian period, a defect also observed in the Rab3 $A^{-1-}$ mouse, but to a lesser degree. The mutation causes a decrease in the ability of the protein to bind guanine nucleotides (both GDP and GTP), without loss of GTPase activity (Yang et al., 2007). The effects on circadian rhythm, as well as sleep homeostatic mechanisms (Kapfhamer et al., 2002) and other behavioral tests (Yang et al., 2007), suggest that Earlybird is a loss-of-function mutation. At neuromuscular junctions expressing additional Rab3 isoforms, malfunctioning Rab3A will be more likely to disrupt function than absent Rab3A.

We first confirmed that the Earlybird mutation acts similarly to loss of Rab3A on the occurrence of abnormal mepcs. The normal variation in amplitude and time course is shown in Figure 2, $A$ and $B$, in overlays of 100 and 94 mepcs for fibers from a wild-type and $R a b 3 A^{E b d / E b d}$ mouse, respectively. The thick white trace is the average mepc trace for the fiber. Miniature endplate currents identified as abnormal by half-widths being outside the Gaussian fit are indicated in the histograms below, shaded in red. The insets show each abnormally wide mepc (red trace) with the average mepc (thick black trace). The increase in percentage of mepcs with abnormally long half-widths in $R a b 3 A^{E b d / E b d}$ mice was almost identical to that of $R a b 3 A^{-1-}$ animals from our previous study (Fig. 2C; Rab3 $A^{-1-}$ data adapted from Wang et al., 2008). We therefore used the Rab3 $A^{\text {Ebd/Ebd }}$ mutant in addition to the Student's $t$ test.
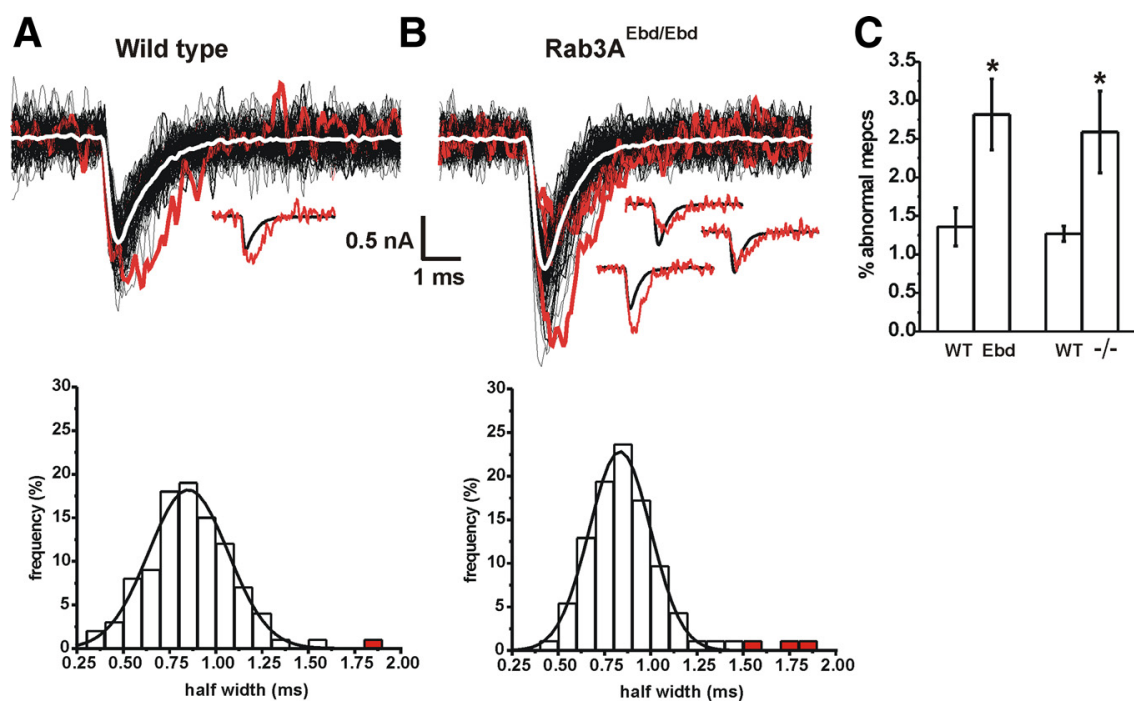

Figure 2. Occurrence of mepcs with abnormally long half-widths is increased in the Rab3A Earlybird (Rab3A $A^{E b d / E b d}$ ) mutant mouse. $A, B$, Top, Overlays of traces recorded in a single fiber from a wild-type sibling (100 traces) and a Rab3A ${ }^{\text {Ebd/Ebd }}$ mouse ( 93 traces), respectively. Thick white traces are averages of all the traces in that fiber; red traces are mepcs with half-widths outside the $p=0.05$ value of the Gaussian fit to the frequency histogram (bottom; outlier half-widths shaded in red). Insets, Individual abnormal mepcs (red) overlaid on the average mepc (black). C, Mean percentage of mepcs with abnormally long half-widths across animals for $\operatorname{Rab} 3 A^{E b d / E b d}(n=6)$ and $\operatorname{Rab} 3 A^{-1-}$ mice $(n=7)$ and their wild-type siblings ( $n=6$ and 8 , respectively). Rab3 $A^{-I-}$ data adapted from Wang et al. (2008). ${ }^{*} p=0.019, R a b 3 A^{E b d / E b d} ; p=0.020$, Rab3 $3 A^{-I-}$. Means were compared with

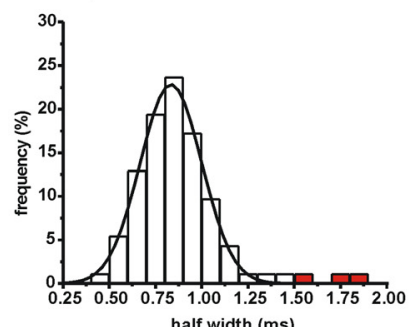

Rab3A deletion mutant to test the role of Rab3A in activitydependent modulation of the occurrence of abnormal mepcs.

Impulse activity in the sciatic nerve was blocked in adult (age 2.5-3.5 months) male and female mice by inserting a TTX cuff and leaving it in place for 7-8 d. TTX was continuously supplied via an osmotic minipump. As was the case in the study by Wang et al. (2008), in each muscle fiber recording we determined the percentage of mepcs that had a half-width that fell outside the $p=$ 0.05 value of a Gaussian fit to the frequency distribution (Fig. 3A, 


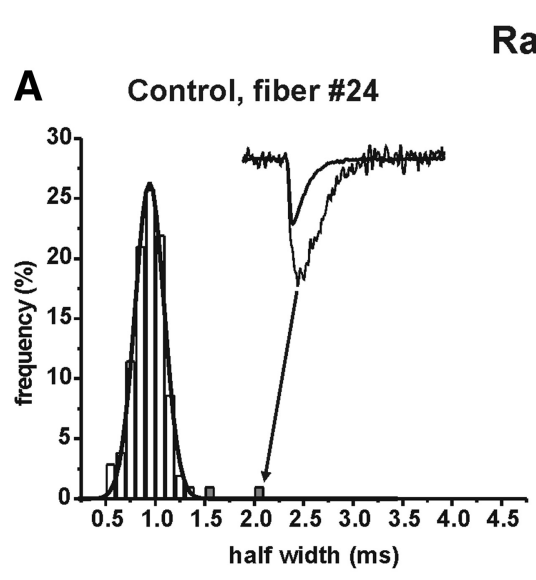

$\operatorname{Rab3A}^{-1-}$

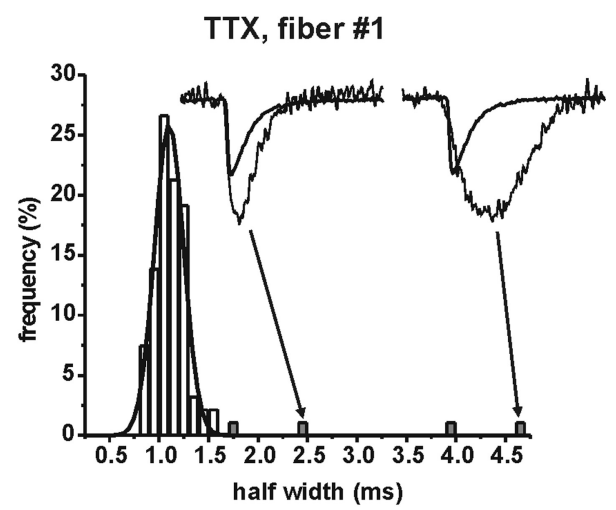

B

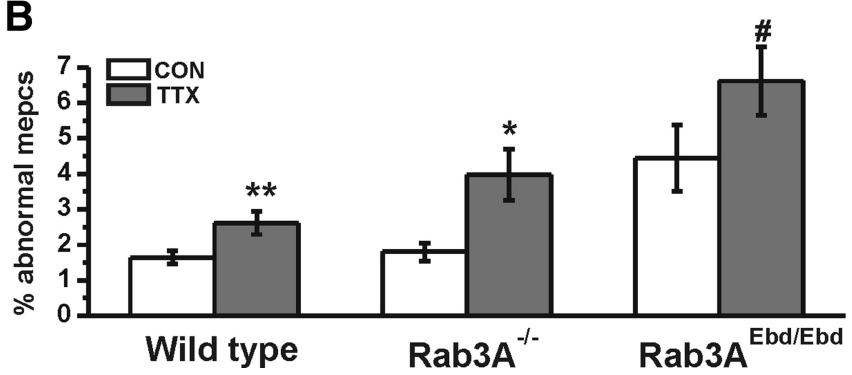

Figure 3. The activity-dependent increase in occurrence of mepcs with abnormally long half-widths is not prevented in $R a b 3 A^{-1-}$ and $R a b 3 A^{E b d / E b d}$ mice. $A$, Frequency histograms for recordings from individual tibialis anterior muscle fibers selected from the untreated ("Control") and TTX-treated sides of a Rab3A ${ }^{-1-}$ mouse. $V_{\mathrm{h}}=-45 \mathrm{mV}$. Half-width values that fell outside the $p=0.05$ value of the Gaussian fit are shaded in gray. Insets, Average mepcs (smooth traces) and abnormal mepcs (noisy traces) with the half-widths indicated by arrows. Control fiber \#24, total = 105 mepcs, abnormal = 2,1.9\%; TTX-treated fiber \#1, total = 95 mepcs, abnormal $=4,4.2 \%$. B . Mean percentage of mepcs with abnormally long half-widths across animals for the untreated [control (CON), open bars] and TTX-treated (TTX), gray bars] sides of wild type ( $n=22$ Rab3A ${ }^{+/+}$animals, pooled from $R a b 3 A^{+/-}$matings and $R a b 3 A^{+/ E b d}$ matings), $R a b 3 A^{-/-}\left(n=16\right.$ animals), and $R a b 3 A^{E b d / E b d}$ ( $n=11$ animals). ${ }^{* *} p=0.012$; ${ }^{*} p=0.022 ;{ }^{\#} p=0.14$, paired $t$ test. Means are \pm SEM.

bars shaded gray), and compared control and TTX-treated neuromuscular junctions. In wild-type animals, the percentage of mepcs with abnormally long half-widths significantly increased after activity blockade (Fig. $3 B, p=0.012, n=22$ ), but only 1.6 -fold (control, $1.64 \pm 0.18 \%$ vs TTX, $2.62 \pm 0.33 \%$ ), much less than that observed by Gundersen (1990) after long-term blockade. This result suggests that the modulatory effect of activity may accumulate with time. Loss of Rab3A did not disrupt activity-dependent modulation of abnormal mepcs. Selected miniature endplate currents with abnormally long half-widths for a control and TTX-treated fiber of a $R a b 3 A^{-1-}$ mouse are shown in the inset in Figure $2 A$, overlaid on the average mepc trace for the same fiber. The percentage of abnormal mepcs increased from $1.80 \pm 0.25 \%$ in untreated neuromuscular junctions to $3.98 \pm 0.72 \%$ in TTX-treated neuromuscular junctions of Rab3A $A^{-1-}$ animals, a 2.2-fold change (Fig. $3 B$ ).

When the TTX cuff experiment was performed in Rab3A Ebd/ $E b d$ mice, we found that a larger percentage of mepcs were abnormal on the TTX-treated side than we have previously observed in any experiment $(6.62 \pm 0.96 \%$, Fig. $3 B)$. However, this was not significantly different from the untreated side in the same animals $(4.44 \pm 0.93 \% ; p=0.14, n=11)$. The lack of significance may be due to the variability in abnormal mepc occurrencesome TTX-treated neuromuscular junctions have 0,1 , or $2 \%$, while others in the same animal have $>15 \%$. Alternatively, the surgery itself may have induced an increase in abnormal mepcs on the untreated side; the percentage of abnormal mepcs ( $4.44 \pm$
$0.93 \%$ ) is larger than that for naive (no surgery) Rab3A ${ }^{E b d / E b d}$ animals (2.82 \pm $0.46 \%)$, but not significantly so ( $p=$ 0.24). In any case, data using two distinct Rab3A alleles do not support the conclusion that Rab3A is required for activitydependent modulation of abnormal mepcs. More likely, loss of Rab3A function makes it easier for activity blockade to increase the occurrence of abnormal mepcs.

We necessarily recorded normal mepcs when we assessed the occurrence of abnormal mepcs. Thus, we made the serendipitous finding that the homeostatic increase in mepc amplitude induced by activity blockade was absent in $R a b 3 A^{E b d}$ Ebd animals. Miniature endplate current recordings from individual fibers of a wild-type sibling show a typical $~ 20 \%$ increase on the TTX-treated side (Fig. 4A). A cumulative plot of all mepcs recorded on the control and TTX-treated sides of this animal (Fig. $4 B$ ) shows that the entire distribution shifts to the right for activityblocked fibers, and there was an increase of $28 \%$ between the control (1.32 \pm 0.06 $\mathrm{nA})$ and TTX-treated animal means (1.69 $\pm 0.04 \mathrm{nA}, p=0.001, n=9)$. In contrast, mepcs recorded from a $R a b 3 A^{\text {Ebd/Ebd }}$ animal did not differ between the two sides (Fig. $4 D, E$ ). Only 1 of 12 animals showed a substantial increase after TTX treatment; some showed a decrease, and the overall mean amplitude was unchanged (control, $1.57 \pm 0.06 \mathrm{nA}$ vs TTX, $1.60 \pm 0.07 \mathrm{nA}, p=0.62, n=12$; Fig. $4 F$ ). As expected from our finding that other Rab3 isoforms are present at the neuromuscular junction, Rab3A deletion did not have as dramatic an effect on homeostatic plasticity (Fig. 5). Compared with their wild-type siblings, where the TTX effect was a highly significant $18 \%$ increase (control, $1.46 \pm 0.04$ vs TTX, $1.73 \pm 0.03, p=$ $0.00003, n=16$; Fig. $5 C$ ), Rab3 $A^{-1-}$ mice responded to activity blockade with greater variability, and although the magnitude was similar, $13 \%$, the statistical significance was much lower (control, $1.48 \pm 0.05 \mathrm{nA}$ vs TTX, $1.67 \pm 0.08 \mathrm{nA}, p=0.022, n=$ 16; Fig. $5 F$ ). The range of responses for different animals is apparent in Figure 5F; some animals showed normal TTX responses, several animals showed very small responses, two showed a decrease, and one animal had an extremely large response. These results are not an artifact of using an average mepc trace to obtain the fiber mean amplitude (see Materials and Methods for details). Data analyzed by taking the mean or median amplitude for individual mepcs in each fiber, then comparing between untreated and treated sides, did not give different results for wild-type or Rab3 $A^{-1-}$ animals.

We observed that there was a $19 \%$ increase in mepc amplitude in $R a b 3 A^{E b d / E b d}$ animals on the untreated side, relative to the untreated side of wild-type controls ( 9 wild-type animals, $1.32 \pm$

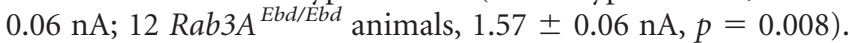
This raised the possibility that a ceiling for mepc amplitude occluded the effect of activity blockade in $R a b 3 A^{E b d / E b d}$ animals. To determine whether there was a relationship between untreated 


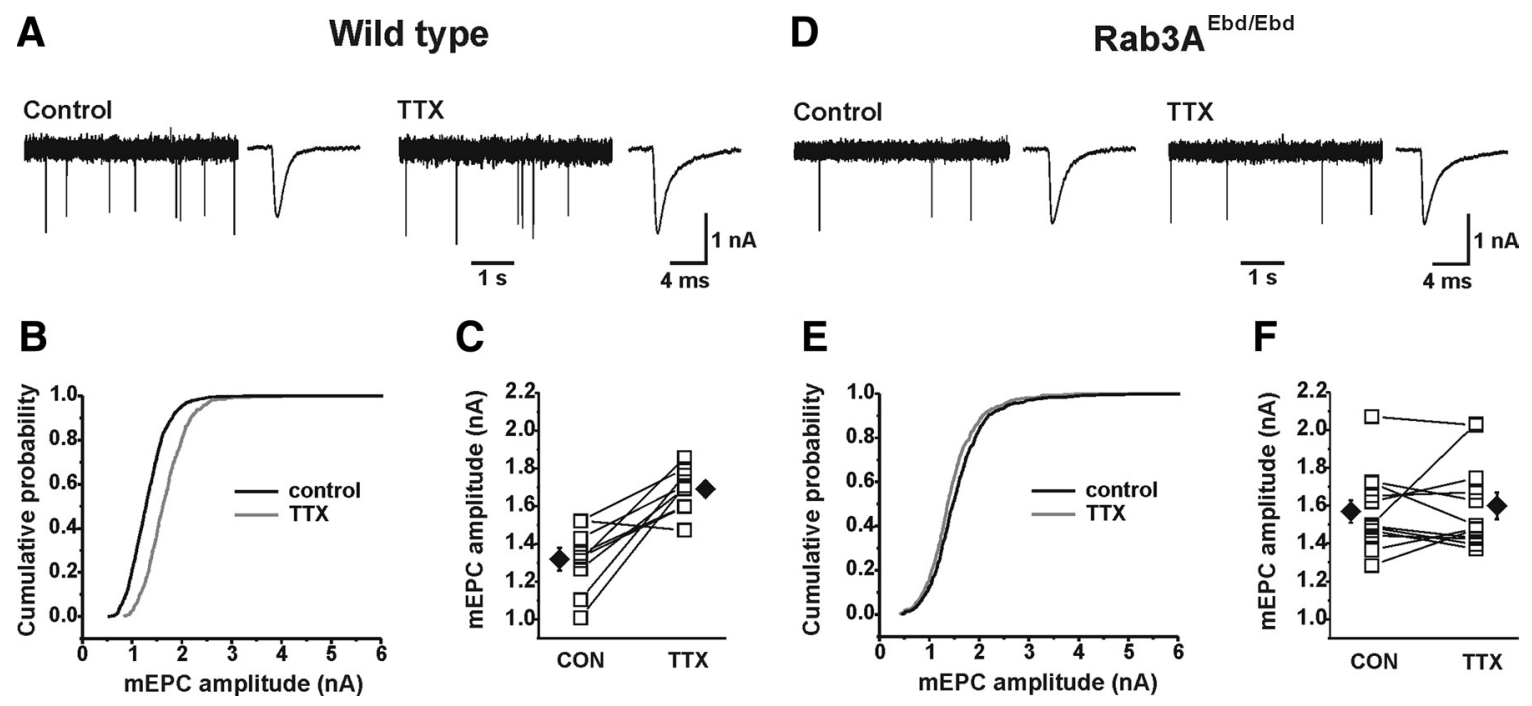

Figure 4. Activity-dependent modulation of mepc amplitude is abolished in Rab3A Earlybird (Rab3A ${ }^{E b d / E b d}$ ) mutant mice. A, Selected 10 s traces of spontaneously occurring mepcs recorded at $-45 \mathrm{mV}$ from untreated (Control) and TTX-treated tibialis anterior muscle fibers in a wild-type mouse from a Rab3A ${ }^{+/ E b d}$ mating. The average mepcs for the recordings are shown on an expanded time scale. $\boldsymbol{B}$, Cumulative plots of mepc amplitudes for the animal from A; 10 control fibers, 980 events; 6 TTX fibers, 597 events. This animal showed a $20 \%$ percentage increase with TTX treatment. C, Individual animal means (open squares) and overall means (closed diamonds) for control and TTX-treated sides of wild-type animals ( $p=0.001, n=9$ animals). D, Selected 10 s traces of mepcs recorded from control and TTX-treated muscle fibers in a Rab3A $A^{E b d / E b d}$ mouse. $\boldsymbol{E}$, Cumulative plots of mepc amplitudes for the animal from $\boldsymbol{D} ; 12$ control fibers, 782 events; 11 TTX fibers, 827 events. This animal showed a $6.5 \%$ decrease with TTX treatment. $F$, Individual animal means (open squares) and overall means (closed diamonds) for control and TTX-treated sides of Rab3A ${ }^{E b d / E b d}$ animals $(p=0.62, n=12$ animals). Means are \pm SEM. Means were compared with a paired $t$ test.

mepc amplitude and the magnitude of homeostatic plasticity, we plotted the percentage increase in mepc amplitude of the TTX-treated side vs the amplitude of the untreated side, for wild-type animals from the Rab3A $A^{+/-}$and Rab3A ${ }^{+/ E b d}$ colonies (Fig. 6A). We found a strong inverse correlation, with the largest percentage increases occurring in animals with the smallest untreated mepc amplitudes $\left(R^{2}\right.$ $=0.73$, combined dataset; $R^{2}=0.57$, wild-type from Rab3$A^{+-}$colony; $R^{2}=$ 0.88 , wild-type from Rab3A ${ }^{+/ E b d}$ colony). The plot in Figure $6 \mathrm{~A}$ suggests a ceiling for mepc amplitude of $1.7 \mathrm{nA}$. However, for both Rab3A ${ }^{-1-}$ (Fig. 6B) and Rab3A Ebd/ Ebd animals (Fig. $6 C$ ), the correlation between percentage increase of the TTXtreated side and the amplitude of the control side was dramatically reduced $\left(R^{2}\right.$ $=0.09$ and 0.12 , respectively). In addition, four Rab3A $A^{E b d / E B d}$ animals with mepc amplitudes $<1.5 \mathrm{nA}$ on the untreated side had no increase with TTX treatment. Therefore the inability of activity blockade to cause an increase in mepc amplitude in Rab3A ${ }^{E b d / E b d}$ animals cannot be solely attributed to larger mepc amplitudes hitting the limit of modulation. Since the percentage change could vary with control mepc amplitude in wild-type animals simply because control amplitude is in the denominator, we also examined the relationship between control amplitude and absolute change (TTX amplitude - control amplitude), and found high $R^{2}$ values for wildtype $\left(R^{2}=0.42\right.$, wild-type from $R a b 3 A^{+1-}$ colony; $R^{2}=0.77$, wild-type from $R a b 3 A^{+/ E b d}$ colony) but not $R a b 3 A^{-1-}\left(R^{2}=\right.$ $0.07)$ or $R a b 3 A^{E b d / E b d}\left(R^{2}=0.12\right)$ animals. compared with a paired $t$ test.
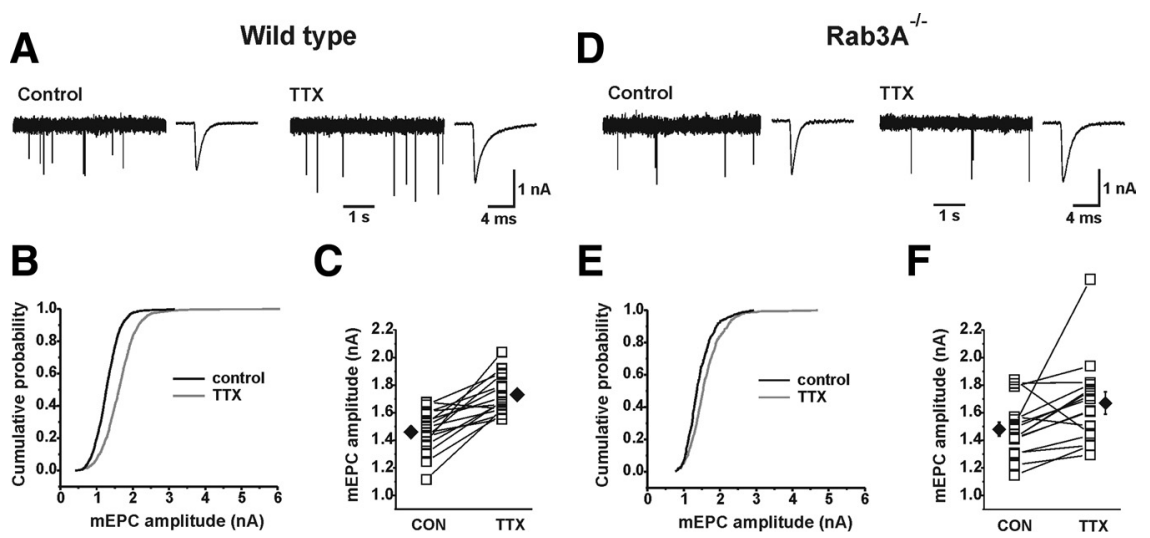

C

E
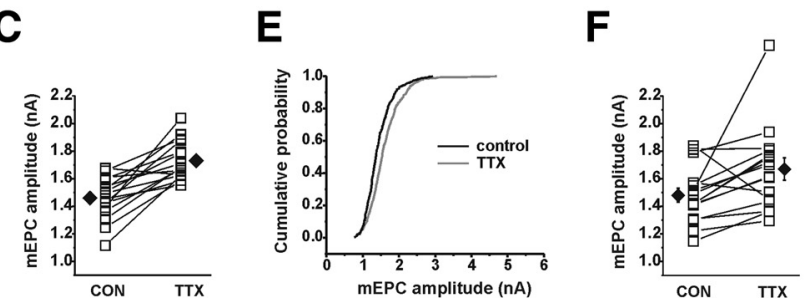

Figure 5. Activity-dependent modulation of mepc amplitude is less robust and more variable in Rab3A deletion mice. $\boldsymbol{A}$ Selected 10 s traces of spontaneously occurring mepcs recorded at $-45 \mathrm{mV}$ from muscle fibers on the untreated (Control) and TTX-treated side of a wild-type mouse from a Rab3A ${ }^{+/-}$mating. The average mepcs for the recordings are shown on an expanded time scale. $\boldsymbol{B}$, Cumulative plots of mepc amplitudes for the animal from A; 16 control fibers, 1433 events; 12 TTX fibers, 1165 events. This animal showed a $27 \%$ increase with TTX treatment. $\boldsymbol{C}$, Individual animal means (open squares) and overall means (closed diamonds) for control and TTX-treated sides of wild-type animals ( $p=0.00003, n=16$ animals). $D$, Selected 10 s traces of mepcs recorded from control and TTX-treated muscle fibers in a Rab3A ${ }^{-1-}$ mouse. $\boldsymbol{E}$, Cumulative plots of mepc amplitudes for the same from D; 6 control fibers, 336 events; 10 TTX fibers, 563 events. This animal showed a 13.5\% increase with TTX treatment. The smaller numbers of fibers and events are due to the decrease in mepc frequency at $R a b 3 A^{-1-}$ neuromuscular junctions, as noted previously (Sons and Plomp, 2006; Coleman et al., 2007). $\boldsymbol{F}$, Individual animal means (open squares) and overall means (closed diamonds) for control and TTX-treated sides of $R a b 3 A^{-1-}$ animals ( $p=0.022, n=16$ animals). Means are \pm SEM. Means were

We previously showed, using carbon fiber amperometry, that loss of Rab3A caused an increase in the occurrence of smallamplitude, long-duration prespike events in adrenal chromaffin cells, which suggested that a defect in fusion pore characteristics could be responsible for mepcs with abnormally long half-widths (Wang et al., 2008). Therefore, we wondered whether the involvement of Rab3A in the homeostatic regulation of mepc amplitude was accompanied by a change in mepc time course consistent with a fusion pore change, such as a longer open time, 

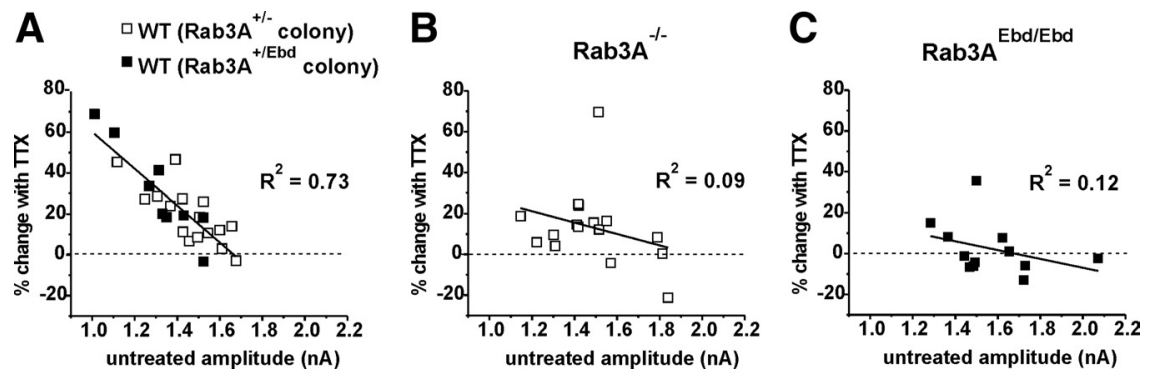

Figure 6. The strong inverse relationship between magnitude of activity-dependent modulation and untreated amplitude is abolished in Rab3A $A^{-1-}$ and Rab3A Earlybird mice. In A-C, the "percent change with TTX" was calculated from [(TTX amplitude untreated amplitude)/untreated amplitude $\left.{ }^{*} 100\right]$, then plotted vs the untreated amplitude; untreated amplitude is the average mepc amplitude from the untreated leg. $A$, Wild-type (open squares, from Rab3$A^{+/-}$matings; closed squares, from Rab3 $3 A^{+/ E b d}$ matings); $\boldsymbol{B}, R a b 3 A^{-I-}$; and $C, R a b 3 A^{E b d / E b d}$ animals. The solid lines are linear regression fits of the data, with $R^{2}$ values as shown.

\section{$\operatorname{Rab} 3 A^{\text {Ebd/Ebd }}$}
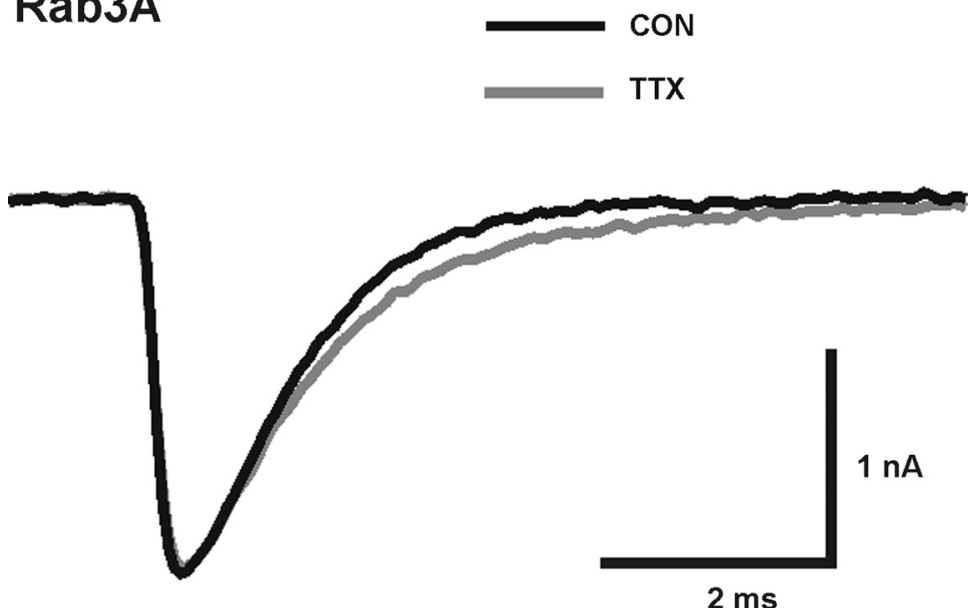

Figure 7. Increased mepc decay time after activity blockade is present in $R a b 3 A^{E b d / E b d}$ animals, despite abolishment of the amplitude increase. Overlay of average mepc traces from a single control (black) and single TTX-treated (gray) fiber in a Rab3A ${ }^{E b d / E b d}$ animal.
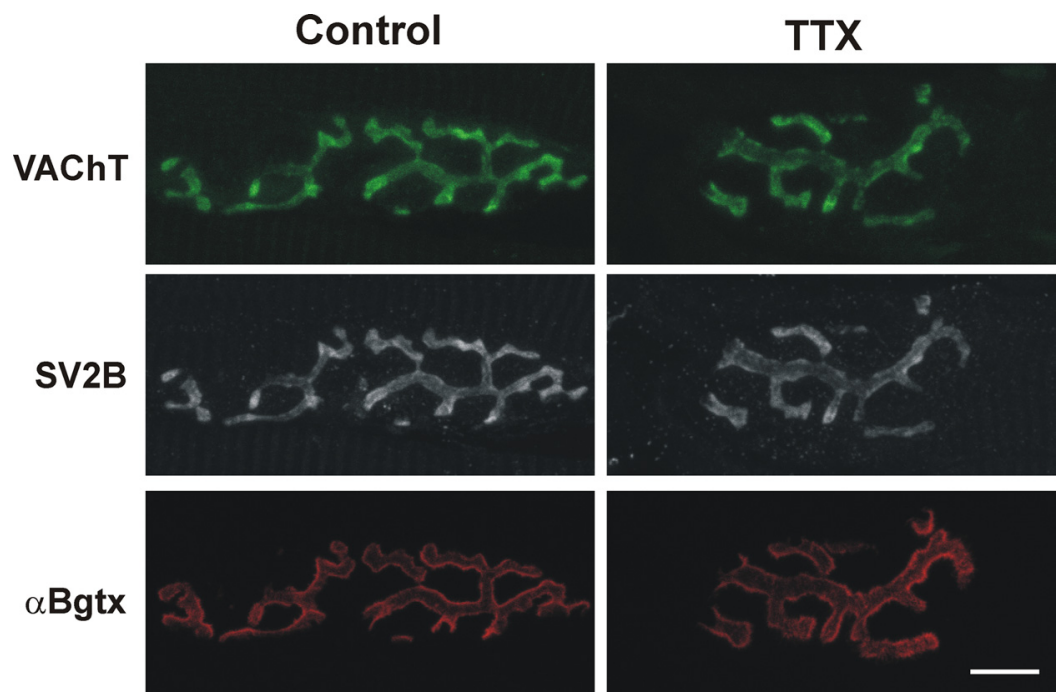

Figure 8. Loss of activity does not alter expression of vesicular transporters or postsynaptic receptors at the neuromuscular junction. Flat-plane confocal images of neuromuscular junctions from the untreated (Control) and TTX-treated sides, respectively, of a wild-type animal, triple labeled for VAChT (green), synaptic vesicle marker SV2B (white), and acetylcholine receptor marker rhodaminated $\alpha$-Bgtx (red). Average intensities across multiple areas of interest in the selected control neuromuscular junction shown were 1462 (VAChT), 1355 (SV2B), and $1011(\alpha$-Btx), and in the selected TTX neuromuscular junction were 1223 (VAChT), 1089 (SV2B), and 1061 ( $\alpha$-Bgtx). Scale bar, $10 \mu \mathrm{m}$. which would manifest as a later time to peak, or a wider pore opening, which would manifest as a faster $10-90 \%$ rise time. To maximize our chances of detecting a subtle change in time course, we selected five wild-type animals from each of the two sets of matings, Rab3A $A^{+/-}$and $R a b 3 A^{+/ E b d}$, with the largest TTX amplitude effects. We were concerned that the presence of abnormal mepcs might affect mean characteristics, so they were removed from the data before analysis. Paired $t$ test comparisons showed that there were no differences in time to peak (untreated, $0.49 \pm 0.02 \mathrm{~ms}$; TTX-treated, $0.50 \pm 0.02 \mathrm{~ms}, p=0.78)$ or $10-90 \%$ rise time (untreated, $0.23 \pm 0.01 \mathrm{~ms}$; TTXtreated, $0.24 \pm 0.01 \mathrm{~ms}, p=0.77)$. For the same selected dataset the amplitude difference was highly significant (untreated, $1.26 \pm 0.04 \mathrm{nA}$; TTX-treated, $1.75 \pm 0.05$ $\mathrm{nA}, p=0.000004) . p$ values are not Bonferroni-corrected for three comparisons. These data do not support a fusion pore mechanism for the TTX-induced increase in mepc amplitude.

Treatment of neuronal cultures with tetrodotoxin causes an increase in the expression of postsynaptic glutamate receptors (O’Brien et al., 1998; Turrigiano et al., 1998). A similar well known phenomenon occurs at the neuromuscular junction. After nerve section or block, ACh receptors are upregulated (Lomo and Rosenthal, 1972), but they are made with a fetal isoform (Witzemann et al., 1987) and are extrasynaptic (Hartzell and Fambrough, 1972; Kues et al., 1995). It was unknown whether the upregulated extrasynaptic fetal receptors contribute to synaptic transmission, but we recently showed using a newly identified fetal receptor-specific toxin (Teichert et al., 2005, 2006) that fetal receptors are responsible for an almost twofold increase in the decay time of the evoked endplate current, and a more modest $14.5 \%$ increase in the decay time of the miniature endplate current (Wang et al., 2006). These results raise the possibility that fetal receptors could be contributing to the amplitude increase following TTX treatment. If so, the abolishment of the amplitude increase in Rab3A Earlybird mutants would be the result of preventing the expression of fetal receptors. To test this idea, we examined the decay times of mepcs in untreated and TTX-treated muscle fibers from a subset of Rab3A Earlybird mutant animals that did not show an amplitude change. Abnormal mepcs were removed before analysis. Figure 7 shows representative average mepc traces for an untreated (black) and a TTX- 
A

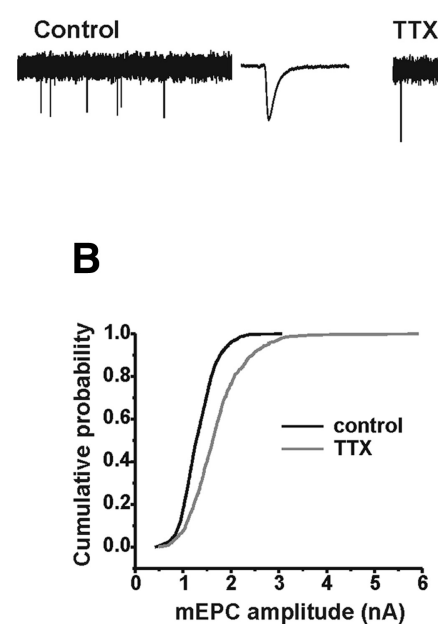

Wild type

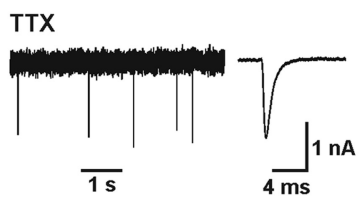

C

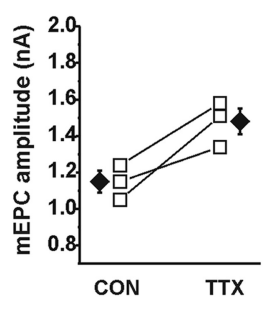

D $\quad \mathrm{TNF}^{-{ }^{-1-}}$

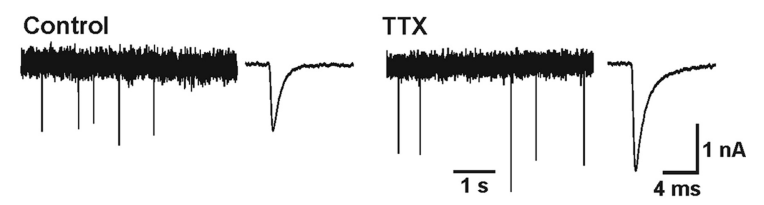

E

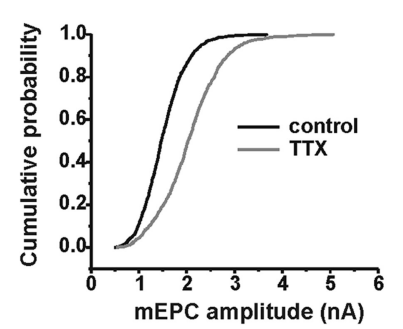

$\mathbf{F}$

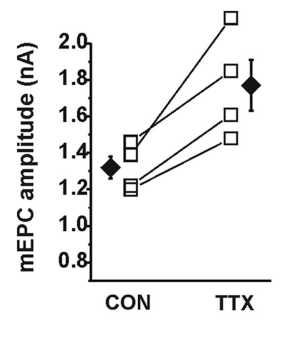

Figure 9. Activity-dependent modulation of mepc amplitude is normal in $T N F \alpha$ deletion mice. $A$, Selected 10 s traces of spontaneously occurring mepcs recorded at $-45 \mathrm{mV}$ from tibialis anterior muscle fibers on the untreated (Control) and TTX-treated side of a wild-type (C57BL/6J) mouse. The average mepcs for the recordings are shown on an expanded time scale. $\boldsymbol{B}$, Cumulative plots of mepc amplitudes for the animal from A; 15 control fibers, 1500 events; 15 TTX fibers, 1216 events. This animal showed a 27\% increase with TTX treatment. C, Individual animal means (open squares) and overall means (closed diamonds) for control and TTX-treated sides of control C57BL/6J animals ( $p=0.050, n=3$ animals). $\boldsymbol{D}$, Selected $10 \mathrm{~s}$ traces of mepcs recorded from control and TTX-treated muscle fibers in a TNF $\alpha^{-1-}$ mouse. $\boldsymbol{E}$, Cumulative plots of mepc amplitudes for the same animal from $\boldsymbol{D} ; 19$ control fibers, 1279 events; 16 TTX fibers, 1092 events. This animal showed a $54 \%$ increase with TTX treatment. $\boldsymbol{F}$, Individual animal means and overall means for control and TTX-treated sides of TNF $\alpha^{-1-}$ animals $(p=0.022, n=4$ animals). Means are \pm SEM. Means were compared with a paired $t$ test.

treated (gray) fiber from a $R a b 3 A^{E b d / E b d}$ mouse. We found that Rab3A Earlybird mutants showed an $18 \%$ increase in decay time (untreated decay, $1.13 \pm 0.08 \mathrm{~ms}$; TTX-treated, $1.34 \pm 0.09 \mathrm{~ms}$; $p=0.046$ ), despite the lack of amplitude increase (untreated amplitude, $1.67 \pm 0.11 \mathrm{nA}$; TTX-treated, $1.61 \pm 0.12 \mathrm{nA}, p=$ $0.15)$. This is strong evidence that fetal receptors continue to be upregulated in Rab3A Earlybird mutants, but the mutant Rab3A disrupts the amplitude increase through some other mechanism.

Studies in neuronal cultures have shown homeostatic changes in the levels of vesicular transporters (De Gois et al., 2005; Wilson et al., 2005; Hartman et al., 2006). To address whether the increase in mepc amplitude might correspond to increased expression of VAChT, we labeled neuromuscular junctions with antibodies to VAChT in combination with anti-SV2B antibodies to label synaptic vesicles, and fluorescent $\alpha$-bungarotoxin to label ACh receptors (Fig. 8). In contrast to studies in neuronal cultures, there was no activity-dependent increase in intensity of VAChT immunoreactivity (untreated pixel intensity, $1128 \pm 64$; TTX-treated, $1225 \pm 103, p=0.28$ ), and its ratio to SV2B showed a trend in the opposite direction (untreated, $1.29 \pm 0.04$; TTXtreated, $1.18 \pm 0.03, p=0.10$ ). In addition, we confirmed that $\alpha$-Bgtx intensity was unchanged after activity blockade (untreated, $1063 \pm 92$; TTX-treated, $1084 \pm 103, p=0.70$ ).

Homeostatic plasticity in neuronal cultures has been shown to depend on postsynaptic receptors, through the action of several different molecules, including arc/arg3.1, $\beta 3$ integrin, and tumor necrosis factor $\alpha$ (TNF $\alpha$ ) (Shepherd et al., 2006; Stellwagen and Malenka, 2006; Kaneko et al., 2008). Since we do not observe an increase in ACh receptors, it is likely that the molecules acting via postsynaptic mechanisms will not play a role in homeostatic plasticity at the neuromuscular junction. To confirm this idea, we performed the TTX cuff experiment in mice lacking TNF $\alpha$. In wild-type C57BL/6J animals, activity blockade caused a 29\% increase in mean mepc amplitude, which was statistically significant with three animals (Fig. $9 A-C ; p=0.050$ ). More importantly, there was a $34 \%$ increase in mean mepc amplitude at the neuromuscular junction of $T N F \alpha^{-1-}$ animals after activity blockade (Fig. 9D-F; $p=0.022, n=4$ animals). Thus homeostatic plasticity at the neuromuscular junction can be distinguished from that of CNS neurons by its lack of dependence on $\mathrm{TNF} \alpha$.

\section{Discussion}

We show that the increase in mepc amplitude that occurs at the mouse neuromuscular junction following activity blockade is diminished in the Rab3A deletion mouse, and abolished in the Rab3A Earlybird mouse. In wild-type animals, the magnitude of plasticity is inversely related to the mepc amplitude of the untreated neuromuscular junctions, and this relationship is disrupted in both the Rab3A deletion and Earlybird mutant mice. These data suggest that normal Rab3A function is required for activity-dependent modulation of mepc amplitude, and that Rab3A also maintains the inverse relationship between the mepc amplitude on the untreated side and the magnitude of the increase on the TTX-treated side. This is the first demonstration that a presynaptic protein, other than a transmitter transporter, is involved in homeostatic plasticity of quantal amplitude.

The mechanism underlying the homeostatic increase in mepc amplitude at the neuromuscular junction differs from homeostatic plasticity of CNS neurons in several respects. It is not accompanied by an increase in postsynaptic ACh receptors (Wang et al., 2005; and this study). In contrast, not only is homeostatic plasticity in the CNS accompanied by changes in postsynaptic receptors (O’Brien et al., 1998; Turrigiano et al., 1998; Wierenga et al., 2005), but molecules required for the plasticity have been shown to regulate receptor expression (Shepherd et al., 2006; Goddard et al., 2007; Aoto et al., 2008; Cingolani et al., 2008). One of these molecules is the cytokine TNF $\alpha$ (Stellwagen and Malenka, 2006), which was not required for homeostatic plasticity at the neuromuscular junction. Activity blockade at the neuromuscular junction had no effect on levels of VAChT, the vesicular transporter for acetylcholine. In contrast, homeostatic 
changes in quantal size in CNS cultures are paralleled by changes in levels of a vesicular glutamate and GABA transporters (De Gois et al., 2005; Wilson et al., 2005; Hartman et al., 2006). Our data strongly suggest that the mechanism underlying homeostatic plasticity of quantal amplitude at the neuromuscular junction is distinct from previously described homeostatic plasticities. It is possible that these different homeostatic plasticities coexist in the CNS to produce maximal synaptic strengthening.

The participation of Rab3A, and the lack of effect on receptor numbers, led us to the idea that quantal amplitude may be modulated through a presynaptic mechanism at the neuromuscular junction. There are three ways that Rab3A could mediate an increase in the presynaptic quantum after activity blockade. It could (1) stimulate the function of VAChT, (2) affect fusion pore kinetics to allow more release, or (3) enlarge the vesicle. VAChT may be continuously regulated by extracellular mediators, since inhibitors of vesicular transport were able to prevent the increase in quantal amplitude induced by $1 \mathrm{~h}$ incubation with TGF $\beta$ at the mammalian neuromuscular junction (Fong et al., 2010). The idea that the mepc does not represent complete vesicle emptying is against the current view, but we recently showed that loss of Rab3A was associated with an increased frequency of abnormal mepcs with slow rises and total charges substantially greater than normal mepcs. We proposed that these events could be the result of a faulty fusion pore that opens to a smaller diameter for a longer period of time (Wang et al., 2008). However, we did not find any evidence that fusion pore kinetics of normal mepcs were altered after activity blockade. While it is possible that changes in fusion pore kinetics large enough to affect mepc amplitude were swamped by other factors such as diffusion, acetylcholinesterase activity, and time course measurement errors of our system (Stiles et al., 1996), the changes would have to be small, since time course differences of $<500 \mu$ s during abnormal mepcs were easily detectable. We therefore favor the first and third possibilities, VAChT activity and vesicle size, which both lead to a greater amount of neurotransmitter in a quantum. In support of the vesicle size idea, Rab3 members have been shown to be involved in vesicle biogenesis (Riedel et al., 2002; Schonn et al., 2010). Finally, we cannot rule out the existence of a Rab3A-dependent anterograde messenger that alters AChR single-channel characteristics, but a post-translational modification of the AChR that increases its single-channel conductance has never been shown.

While we have focused on the contrast between TTX-induced plasticity of mepcs and that of miniature excitatory synaptic currents, TTX-induced plasticity of miniature inhibitory synaptic currents (mipscs) may be a better match. In hippocampal cultures, TTX treatment causes a decrease in mipsc amplitude, but no change in expression of the $\beta 2 / 3$ subunits of the GABA receptor. In addition, a competitive antagonist is more effective at reducing mipsc amplitude (Hartman et al., 2006). These data indicate that the inhibitory presynaptic quantum is being modulated by TTX treatment. However, the match between TTXinduced plasticity of mepcs and mipscs is not perfect, because the latter is sensitive to a scavenger of $\mathrm{TNF} \alpha$ (Stellwagen and Malenka, 2006), and is accompanied by changes in GABA transporter expression (Hartman et al., 2006; see also De Gois et al., 2005).

The use of the Rab3A Earlybird mutant allowed us to observe a complete disruption of the homeostatic increase in mepc amplitude at the neuromuscular junction after activity blockade, while deletion of Rab3A had a similar, but less dramatic effect. There is precedence for a mutant having a more dramatic phenotype than the deletion. The temperature-sensitive dynamin mu- tant shibire can abolish all endocytosis in Drosophila neurons, with almost complete depletion of synaptic terminals after stimulation (Kosaka and Ikeda, 1983), but loss of dynamin I in the mouse only modestly impairs slow endocytosis following repetitive stimulation (Ferguson et al., 2007; Lou et al., 2008). We demonstrated that Rab3 $A^{-1-}$ neuromuscular junctions express other isoforms of Rab3, and we believe that the difference in ability of the point mutant and deletion mutant to prevent homeostatic plasticity is explained by compensation of other Rab3s for the absent protein, but not for the altered protein.

In conclusion, we describe a novel form of homeostatic plasticity at the mammalian neuromuscular junction that depends on the presynaptic protein Rab3A. Since Rab3A is expressed throughout the nervous system, some forms of CNS homeostatic plasticity may also depend on Rab3A. Furthermore, while Rab3A has previously been thought to regulate the number of vesicles that fuse during stimulation, our work opens the possibility that some forms of Rab3A-dependent plasticity may involve modulation of quantal characteristics.

\section{References}

Alkadhi KA (1989) Giant miniature end-plate potentials at the untreated and emetine-treated frog neuromuscular junction. J Physiol 412:475-491.

Aoto J, Nam CI, Poon MM, Ting P, Chen L (2008) Synaptic signaling by all-trans retinoic acid in homeostatic synaptic plasticity. Neuron 60:308-320.

Castillo PE, Janz R, Südhof TC, Tzounopoulos T, Malenka RC, Nicoll RA (1997) Rab3A is essential for mossy fibre long-term potentiation in the hippocampus. Nature 388:590-593.

Cheng H, Ma Y, Ni X, Jiang M, Luo Y, Ying K, Xie Y (2002) Cloning, mapping, and characterization of the human Rab3C gene. Biochem Genet 40:263-272.

Cingolani LA, Thalhammer A, Yu LM, Catalano M, Ramos T, Colicos MA, Goda Y (2008) Activity-dependent regulation of synaptic AMPA receptor composition and abundance by beta3 integrins. Neuron 58:749-762.

Coleman WL, Bill CA, Bykhovskaia M (2007) Rab3a deletion reduces vesicle docking and transmitter release at the mouse diaphragm synapse. Neuroscience 148:1-6.

De Gois S, Schäfer MK, Defamie N, Chen C, Ricci A, Weihe E, Varoqui H, Erickson JD (2005) Homeostatic scaling of vesicular glutamate and GABA transporter expression in rat neocortical circuits. J Neurosci 25:7121-7133.

Ferguson SM, Brasnjo G, Hayashi M, Wölfel M, Collesi C, Giovedi S, Raimondi A, Gong LW, Ariel P, Paradise S, O’toole E, Flavell R, Cremona O, Miesenböck G, Ryan TA, De Camilli P (2007) A selective activitydependent requirement for dynamin 1 in synaptic vesicle endocytosis. Science 316:570-574.

Fong SW, McLennan IS, McIntyre A, Reid J, Shennan KI, Bewick GS (2010) TGF-beta2 alters the characteristics of the neuromuscular junction by regulating presynaptic quantal size. Proc Natl Acad Sci USA 107:13515-13519.

Goddard CA, Butts DA, Shatz CJ (2007) Regulation of CNS synapses by neuronal MHC class I. Proc Natl Acad Sci U S A 104:6828-6833.

Gundersen K (1990) Spontaneous activity at long-term silenced synapses in rat muscle. J Physiol 430:399-418.

Hartman KN, Pal SK, Burrone J, Murthy VN (2006) Activity-dependent regulation of inhibitory synaptic transmission in hippocampal neurons. Nat Neurosci 9:642-649.

Hartzell HC, Fambrough DM (1972) Acetylcholine receptors. Distribution and extrajunctional density in rat diaphragm after denervation correlated with acetylcholine sensitivity. J Gen Physiol 60:248-262.

Huang YY, Zakharenko SS, Schoch S, Kaeser PS, Janz R, Südhof TC, Siegelbaum SA, Kandel ER (2005) Genetic evidence for a protein-kinase-Amediated presynaptic component in NMDA-receptor-dependent forms of long-term synaptic potentiation. Proc Natl Acad Sci USA 102:9365-9370.

Kaneko M, Stellwagen D, Malenka RC, Stryker MP (2008) Tumor necrosis factor-alpha mediates one component of competitive, experiencedependent plasticity in developing visual cortex. Neuron 58:673-680. 
Kapfhamer D, Valladares O, Sun Y, Nolan PM, Rux JJ, Arnold SE, Veasey SC, Bućan M (2002) Mutations in Rab3a alter circadian period and homeostatic response to sleep loss in the mouse. Nat Genet 32:290-295.

Kosaka T, Ikeda K (1983) Possible temperature-dependent blockage of synaptic vesicle recycling induced by a single gene mutation in Drosophila. J Neurobiol 14:207-225.

Kues WA, Brenner HR, Sakmann B, Witzemann V (1995) Local neurotrophic repression of gene transcripts encoding fetal AChRs at rat neuromuscular synapses. J Cell Biol 130:949-957.

Lissin DV, Gomperts SN, Carroll RC, Christine CW, Kalman D, Kitamura M, Hardy S, Nicoll RA, Malenka RC, von Zastrow M (1998) Activity differentially regulates the surface expression of synaptic AMPA and NMDA glutamate receptors. Proc Natl Acad Sci U S A 95:7097-7102.

Lomo T, Rosenthal J (1972) Control of ACh sensitivity by muscle activity in the rat. J Physiol 221:493-513.

Lou X, Paradise S, Ferguson SM, De Camilli P (2008) Selective saturation of slow endocytosis at a giant glutamatergic central synapse lacking dynamin 1. Proc Natl Acad Sci U S A 105:17555-17560.

Marder E, Goaillard JM (2006) Variability, compensation and homeostasis in neuron and network function. Nat Rev Neurosci 7:563-574.

Matteoli M, Takei K, Cameron R, Hurlbut P, Johnston PA, Südhof TC, Jahn R, De Camilli P (1991) Association of Rab3A with synaptic vesicles at late stages of the secretory pathway. J Cell Biol 115:625-633.

Mizoguchi A, Arakawa M, Masutani M, Tamekane A, Yamaguchi H, Minami N, Takai Y, Ide C (1992) Localization of smg p25A/rab3A p25, a small GTP-binding protein, at the active zone of the rat neuromuscular junction. Biochem Biophys Res Commun 186:1345-1352.

O'Brien RJ, Kamboj S, Ehlers MD, Rosen KR, Fischbach GD, Huganir RL (1998) Activity-dependent modulation of synaptic AMPA receptor accumulation. Neuron 21:1067-1078.

Pozo K, Goda Y (2010) Unraveling mechanisms of homeostatic synaptic plasticity. Neuron 66:337-351.

Rich MM, Wenner P (2007) Sensing and expressing homeostatic synaptic plasticity. Trends Neurosci 30:119-125.

Riedel D, Antonin W, Fernandez-Chacon R, Alvarez de Toledo G, Jo T, Geppert M, Valentijn JA, Valentijn K, Jamieson JD, Südhof TC, Jahn R (2002) Rab3D is not required for exocrine exocytosis but for maintenance of normally sized secretory granules. Mol Cell Biol 22:6487-6497.

Schlüter OM, Schmitz F, Jahn R, Rosenmund C, Südhof TC (2004) A complete genetic analysis of neuronal Rab3 function. J Neurosci 24:6629-6637.

Schonn JS, van Weering JR, Mohrmann R, Schlüter OM, Südhof TC, de Wit H, Verhage M, Sørensen JB (2010) Rab3 proteins involved in vesicle biogenesis and priming in embryonic mouse chromaffin cells. Traffic 11:1415-1428.

Shepherd JD, Rumbaugh G, Wu J, Chowdhury S, Plath N, Kuhl D, Huganir RL, Worley PF (2006) Arc/Arg3.1 mediates homeostatic synaptic scaling of AMPA receptors. Neuron 52:475-484.

Snider WD, Harris GL (1979) A physiological correlate of disuse-induced sprouting at the neuromuscular junction. Nature 281:69-71.
Sons MS, Plomp JJ (2006) Rab3A deletion selectively reduces spontaneous neurotransmitter release at the mouse neuromuscular synapse. Brain Res 1089:126-134.

Stellwagen D, Malenka RC (2006) Synaptic scaling mediated by glial TNFalpha. Nature 440:1054-1059.

Stiles JR, Van Helden D, Bartol TM Jr, Salpeter EE, Salpeter MM (1996) Miniature endplate current rise times less than 100 microseconds from improved dual recordings can be modeled with passive acetylcholine diffusion from a synaptic vesicle. Proc Natl Acad Sci U S A 93:5747-5752.

Teichert RW, Rivier J, Torres J, Dykert J, Miller C, Olivera BM (2005) A uniquely selective inhibitor of the mammalian fetal neuromuscular nicotinic acetylcholine receptor. J Neurosci 25:732-736.

Teichert RW, López-Vera E, Gulyas J, Watkins M, Rivier J, Olivera BM (2006) Definition and characterization of the short alphaA-conotoxins: a single residue determines dissociation kinetics from the fetal muscle nicotinic acetylcholine receptor. Biochemistry 45:1304-1312.

Thakker-Varia S, Alder J, Crozier RA, Plummer MR, Black IB (2001) Rab3A is required for brain-derived neurotrophic factor-induced synaptic plasticity: transcriptional analysis at the population and single-cell levels. J Neurosci 21:6782-6790.

Turrigiano GG (2008) The self-tuning neuron: synaptic scaling of excitatory synapses. Cell 135:422-435.

Turrigiano GG, Leslie KR, Desai NS, Rutherford LC, Nelson SB (1998) Activity-dependent scaling of quantal amplitude in neocortical neurons. Nature 391:892-896.

Wang X, Li Y, Engisch KL, Nakanishi ST, Dodson SE, Miller GW, Cope TC, Pinter MJ, Rich MM (2005) Activity-dependent presynaptic regulation of quantal size at the mammalian neuromuscular junction in vivo. J Neurosci 25:343-351.

Wang X, Engisch KL, Teichert RW, Olivera BM, Pinter MJ, Rich MM (2006) Prolongation of evoked and spontaneous synaptic currents at the neuromuscular junction after activity blockade is caused by the upregulation of fetal acetylcholine receptors. J Neurosci 26:8983-8987.

Wang X, Thiagarajan R, Wang Q, Tewolde T, Rich MM, Engisch KL (2008) Regulation of quantal shape by Rab3A: evidence for a fusion poredependent mechanism. J Physiol 586:3949-3962.

Wang X, Wang Q, Engisch KL, Rich MM (2010) Activity-dependent regulation of the binomial parameters $\mathrm{p}$ and $\mathrm{n}$ at the mouse neuromuscular junction in vivo. J Neurophysiol 104:2352-2358.

Wierenga CJ, Ibata K, Turrigiano GG (2005) Postsynaptic expression of homeostatic plasticity at neocortical synapses. J Neurosci 25:2895-2905.

Wilson NR, Kang J, Hueske EV, Leung T, Varoqui H, Murnick JG, Erickson JD, Liu G (2005) Presynaptic regulation of quantal size by the vesicular glutamate transporter VGLUT1. J Neurosci 25:6221-6234.

Witzemann V, Barg B, Nishikawa Y, Sakmann B, Numa S (1987) Differential regulation of muscle acetylcholine receptor gamma- and epsilonsubunit mRNAs. FEBS Lett 223:104-112.

Yang S, Farias M, Kapfhamer D, Tobias J, Grant G, Abel T, Bućan M (2007) Biochemical, molecular and behavioral phenotypes of Rab3A mutations in the mouse. Genes Brain Behav 6:77-96. 